UDC 04.316:303; 316:001.8

LBC 60.5

\title{
THE SPHERE OF REGIONAL CULTURE IN INDICATORS AND ASSESSMENT
}

\author{
Tatyana V. Andriyanova \\ Kursk State University, Kursk, Russian Federation
}

\begin{abstract}
Sociological methods and mathematical analysis and their application to measure key indicators of regional culture are revealed in the article. As the main model of the study is an independent assessment of the quality of services rendered by cultural organizations of the region. Basic research methods: a mathematical procedure for determining integrated values of transparency in the organization culture and recipients satisfaction of its services, the overall score of the organization. Also methods of analysis of documents and information of the web-sites of bodies of culture management for the purpose of a more in-depth analysis of the data. The peculiarities of this technique lie in its universal character for all types of cultural organizations throughout the country for obtaining objective information in the form of numerical values. Limitations of its application are described by the author on the basis of their own experience in carrying out an independent assessment of the quality of services of culture institutions in the Kursk region. The results are presented in the overall scoring of each culture institution of the region from a list of independent evaluations with grouping into indicators. This allowed the authorities to develop a system of measures to improve the quality of work of cultural institutions. The most important indicator in 2017 is availability of services for people with disabilities. According to the said above and taking into consideration other actual directions the procedure and methods of independent quality assessment are corrected and it allows to make a conclusion about its powerful research capacity for culture in the region.

Key words: regional culture, independent assessment of the quality of services, indicators, organization's culture, service recipients' opinion.
\end{abstract}

УДК 04.316:303; 316:001.8

ББК 60.5

\section{СФЕРА РЕГИОНАЛЬНОЙ КУЛЬТУРЫ В ПОКАЗАТЕЛЯХ И ОЦЕНКАХ}

\section{Татьяна Владимировна Андриянова}

Курский государственный университет, г. Курск, Российская Федерация

\begin{abstract}
Аннотация. В статье раскрывается сущность применения методов социологического и математического анализа для измерения основных показателей региональной культуры. В качестве основной модели исследования выступает проведение независимой оценки качества оказания услуг организациями культуры региона. Основными методами являются математические процедуры определения интегральных значений открытости данных организации культуры и удовлетворенности получателями ее услуг, определение общего балла организации. Кроме этого применялись методы анализа документов и информационных материалов веб-сайтов органов управления культурой с целью более углубленного анализа полученных данных. Особенности этой методики заключаются в универсальном характере ее применения для всех типов организаций культуры на всей территории РФ для получения объективной информации в виде числовых значений. Ограничения ее применеㄱ ния описаны автором в статье на основе собственного опыта работы в рамках проведения независимой оценки ‥ качества оказания услуг учреждениями культуры на базе регионального оператора в Курской области. Результаты исследования представлены в виде общей балльной оценки каждого учреждения культуры региона из списка подлежащих независимой оценке с разбивкой по показателям. Это дало возможность представителям органов власти адресно разработать систему мер по повышению качества работы учреждений культуры. С 2017 г. среди наиболее важных показателей выделяется доступность услуг для инвалидов. С учетом этого, а также других актуальных направлений корректируется процедура и методы независимой оценки качества, что () позволяет сделать вывод о ее мощном исследовательском потенциале для сферы культуры региона.
\end{abstract}


Ключевые слова: региональная культура, независимая оценка качества оказания услуг, показатели, организации культуры, мнение получателей услуг.

Региональная культура занимает особое место в культуре России, ее роль ученые определяют как ведущую во многих социальных процессах, протекающих в обществе. Региональный аспект исследований становится все более заметным в общем массиве. Он способствует осознанию современной ситуации в политике, экономике, социальной сфере, куда относятся и региональные учреждения культуры. Каждый регион стремится к формированию полной картины социального развития, для того чтобы выработать стратегию ее дальнейшего совершенствования. С этой целью создаются «дорожные карты», «атласы», «паспорта» социокультурного развития. Немаловажное значение здесь имеет независимая оценка качества оказания услуг учреждениями культуры, которая позволяет в социологическом измерении представить ситуацию в отрасли. В Курской области она проводится с 2015 г. [1], как и на территории всей Российской Федерации. Правовую основу оценки составляют следующие нормативные документы:

- «Основы законодательства Российской Федерации о культуре», 1992 г. [1];

- Указ Президента Российской Федерации «О мероприятиях по реализации государственной социальной политики», 2012 г. [11];

- приказы Министерства культуры Российской Федерации, 2015-2017 гг. [3-7].

Согласно вышеприведенным документам, независимая оценка качества оказания услуг не может осуществляться в процессе создания, интерпретации и исполнения произведений литературы и искусства. В приказе
Минкультуры РФ № 2169 существует перечень организаций культуры, куда входят 15 организаций, не оказывающих услуги населению, для которых не проводится независимая оценка качества оказания услуг [5].

Региональная сфера культуры имеет свои особенности, которые учитываются при формировании и оценке стратегии ее развития. С этой целью комитет по культуре Курской области разработал и утвердил План мероприятий по проведению независимой оценки качества работы организаций, оказывающих услуги в сфере культуры, на 2016-2018 гг. (далее - План). Органам управления районов и городов Курской области в сфере культуры рекомендовано также на своем уровне разработать и утвердить план мероприятий независимой оценки, включающей целевые показатели, в том числе долю охваченных ею организаций культуры, расположенных на территории муниципального образования [2]. В Курской области 33 муниципальных образования, из числа которых 28 - районного типа и 5 городского (г. Курск, Железногорск, Курчатов, Льгов, Щигры).

Целевые показатели независимой оценки качества оказания услуг организациями культуры Курской области представлены следующим образом (табл. 1).

Из приведенной таблицы видно, что всего в Курской области 45 организаций, оказывающих услуги в сфере культуры разного типа (библиотеки, музеи, театры, филармония и т. д.), и муниципальных органов управления, которые обеспечивают возможность онлайнопроса населения в ходе независимой оценки, начиная с 2015 года.

Таблица 1

Целевые показатели независимой оценки качества оказания услуг организациями культуры Курской области

\begin{tabular}{|c|l|c|c|c|c|}
\hline № & \multicolumn{1}{|c|}{ Целевые показатели } & 2015 г. & 2016 г. & 2017 г. & 2018 г. \\
\hline 1 & $\begin{array}{l}\text { Доля организаций культуры, охваченных независимой оценкой, от } \\
\text { общего количества организаций культуры (с нарастающим итогом, на- } \\
\text { чиная с 2016 г.), \% }\end{array}$ & 20,0 & 55,0 & 75,0 & 100,0 \\
\hline 2 & $\begin{array}{l}\text { Количество областных организаций культуры и муниципальных орга- } \\
\text { нов управления в сфере культуры, на официальных сайтах которых } \\
\text { обеспечена техническая возможность выражения мнения граждан о } \\
\text { качестве оказанных услуг (размещение анкеты для интернет-опроса) }\end{array}$ & - & 45 & 45 & 45 \\
\hline
\end{tabular}




\section{СОЦИОЛОГИЯ И СОЦИАЛЬНЫЕ ТЕХНОЛОГИИ}

Все мероприятия Плана разделены на два организационных уровня: региональный и муниципальный. Первый включает в себя кроме комитета по культуре и его структурных подразделений (отдел культурно-досуговой деятельности) также организации культуры, находящиеся в подчинении комитета по культуре, и Общественный совет при комитете по культуре. Деятельностный аспект здесь выражается в организации и проведении независимой оценки качества оказания услуг организациями культуры и ее технического сопровождения. Сюда относится: обеспечение для получателей услуг технической возможности выразить свое мнение; размещение на официальном сайте государственных организаций информации о результатах независимой оценки; размещение информации о своей деятельности организациями культуры на собственных официальных сайтах; своевременная модерация раздела «Независимая оценка» на официальном сайте комитета по культуре Курской области. Контролирующие функции в Плане заключаются в постоянном мониторинге показателей организаций культуры по мере поступления предложений и замечаний об их работе.

Второй уровень отвечает за отработку вышеизложенных требований на уровне муниципальных образований. Сюда относится: организационно-методическое сопровождение проведения независимой оценки качества, организация мероприятий независимой оценки качества, мониторинг открытости данных о результатах независимой оценки качества, формирование рейтинга организаций культуры по результатам оценки, подведение итогов по достижению целевых показателей организациями, охваченными независимой оценкой качества.

Особую роль в проведении независимой оценки качества оказания услуг организациями культуры Курской области и обеспечении ее объективных результатов играют муниципальные органы управления. В Рейтинге муниципальных районов и городских округов в сфере культуры по итогам 2016 г. [10; 12] в качестве основания показателя «Эффективность деятельности органов управления в сфере культуры» был взят такой важный критерий, как «образовательный уровень» для му- ниципальных учреждений культуры, для муниципальных библиотек, для муниципальных учреждений культурно-досугового типа, исходя из 100 баллов. На его основе можно сделать выводы, что в городах работают люди с более высоким образовательным уровнем, чем в районных организациях; удаленность районов от областного центра не является фактором, понижающим образовательный уровень; на уровне одного муниципального образования рейтинг в трех категориях может отличаться на значительное количество позиций. Зафиксированные минимумы образовательного уровня по группам (муниципальные учреждения культуры - 35,4 балла; муниципальные библиотеки - 48,7 балла; муниципальные учреждения культурно-досугового типа 20,9 балла) дают основание говорить о наиболее неблагополучной «образовательной картине» среди последней категории работников. А максимумы (соответственно - 92,9 балла; 98,3 балла; 88,7 балла) практически уравнивают позиции в первых двух группах на достаточно высоком значении показателя.

Среди других показателей Рейтинга можно выделить важные для независимой оценки качества оказания услуг организациями культуры: «Кинообслуживание населения» и «Библиотечное обслуживание».

В сфере кинообслуживания в Курской области насчитывается 245 киноустановок. В верхних позициях рейтинга зафиксировано в среднем 36,4 зрителя на киносеансе с учетом вместимости зала на 50 мест, что говорит в целом о значительной активности зрительской аудитории.

Библиотечное обслуживание в Курской области осуществляют 694 муниципальные библиотеки, что в целом соответствует $41,4 \%$ охвата населения. Из них 55,2 \% составляют компьютеризированные библиотеки и 50,6 \% с выходом в интернет. В тройку лучших библиотек входят городские учреждения со $100 \%$-ной компьютеризацией и возможностью выхода в интернет.

Независимая оценка качества оказания услуг в Курской области в 2017 г. осуществляется в соответствии с Приказом Министерства культуры РФ № 2542. По сравнению с ранее действующим приказом от 2015 г. [4], список организаций культуры включает в себя 
не только библиотеки, музеи, театры, культурно-досуговые организации, но и парки культуры и отдыха, цирки, зоопарки, кинотеатры и иные организации культуры. Это, с одной стороны, расширяет возможности проведения независимой оценки качества, с другой - ограничивает ее условия, так как нет возможности учесть специфику организаций разного типа. Для всех них разработаны одинаковые показатели в рамках унифицированной модели.

Так, показатель «Открытость и доступность информации об организации культуры» (0-30 баллов) измеряется с помощью доступности и актуальности информации о деятельности организации культуры, размещенной на территории организации, наличия информации о деятельности организации культуры на официальном сайте организации культуры в сети «Интернет», наличия общей информации об организации культуры на официальном сайте организации культуры в сети «Интернет».

Показатель «Комфортность условий предоставления услуг и доступность их получения» (0-50 баллов) измеряется с учетом комфортности условий пребывания в организации культуры, наличия дополнительных услуг и доступности их получения, удобства пользования электронными сервисами, предоставляемыми организацией культуры (в том числе с помощью мобильных устройств), удобства графика работы организации культуры, доступности услуг для лиц с ограниченными возможностями здоровья. Хотелось бы отметить, что последний пункт появился в рекомендациях начиная с 2017 г. с целью обеспечения доступной жизненной среды для лиц с ограниченными возможностями здоровья.

Показатель «Время ожидания предоставления услуги» (0-20 баллов) основывается на соблюдении режима работы организацией культуры, соблюдении установленных (заявленных) сроков предоставления услуг организацией культуры.

Показатель «Доброжелательность, вежливость, компетентность работников организации культуры» (0-20 баллов) измеряется как сумма этих критериев.

Показатель «Удовлетворенность качеством оказания услуг» (0-40 баллов)определяется посредством замера удовлетворенно- сти качеством и полнотой информации о деятельности организации культуры, размещенной на официальном сайте организации культуры в сети «Интернет», удовлетворенности качеством и содержанием полиграфических материалов организации культуры, удовлетворенности материально-техническим обеспечением организации культуры, общей удовлетворенности качеством оказания услуг организацией культуры.

В качестве источника сбора, обобщения и анализа информации для всех показателей служат официальные сайты организаций культуры и изучение мнения получателей услуг.

В Методических рекомендациях по проведению независимой оценки качества оказания услуг организациями культуры (далее Рекомендации) [7] указывается, что организации культуры размещают на своих официальных сайтах анкету в интерактивной форме для обеспечения технической возможности выражения мнений получателей услуг о качестве их оказания. В качестве основных каналов сбора информации рекомендуются следующие:

- электронная почта: опрос получателей услуг путем отправки электронного сообщения с формой анкеты для заполнения получателем услуги и последующей отправкой заполненной анкеты по электронной почте;

- опрос по телефону: опрос получателей услуг организаций культуры по каналам телефонной связи в устной форме с последующим занесением данных в анкету;

- личный опрос (социологическое исследование): опрос получателей услуг в устной форме с последующим занесением данных в анкету либо заполнение получателем услуг анкеты на бумажном носителе;

- интернет-канал: опрос получателей услуг путем заполнения в информационно-телекоммуникационной сети «Интернет» анкеты в интерактивной форме;

- терминал в организации культуры: опрос получателей услуг путем заполнения анкеты в интерактивной форме через терминал.

В Рекомендациях все организации культуры разделены на три категории в зависимости от количества получателей услуг в год: малые организации культуры (до 12 000), средние организации культуры (от 12000 до 50 000), 
крупные организации культуры (от 50 000). Такая градация необходима для получения объективной картины удовлетворенности получателей услуг качеством оказания услуг организациями культуры и определения необходимого количества собираемых анкет: 150 / 500 / 1000.

Характеризующие общие критерии оценки качества оказания услуг организациями культуры показатели и расчет их значений осуществляются на основании анализа информации, представленной на официальном сайте организации культуры, и по результатам данных, полученных при изучении мнений получателей услуг [9].

Общая оценка по каждому показателю и в их совокупности измеряется в баллах, где $\min =0, \max =160$ баллов. Формула для вычисления общего балла: $N_{i}=N_{i}^{\text {откр }}+N_{i}^{\text {удовл }}$, где $N_{i}$ - общий балл $i$-й организации культуры по итогам независимой оценки качества оказания услуг; $N_{i}^{\text {откр }}$ - интегральное значение показателей, определяемых путем анализа информации, размещенной на официальном сайте $i$-й организации культуры; $N_{i}^{\text {удовл }}-$ интегральное значение показателей, определяемых путем анализа данных, полученных при изучении мнений получателей услуг $i$-й организации культуры.

Интегральное значение показателей $i$-й организации культуры, определяемое путем анализа информации, размещенной на официальном сайте $\left(N_{i}^{\text {откр }}\right)$, рассчитывается по формуле:

$$
N_{i}^{\text {oткр }}=\sum_{s} \sum_{k} Z_{i k s}
$$

где $Z_{i k s}-$ интегральное значение уровня поисковой доступности $k$-го информационного объекта, размещенного на официальном сайте $i$-й организации культуры, по $s$-му показателю, характеризующему общие критерии качества оказания услуг.

На официальном сайте организации культуры осуществляется поиск информационных объектов с использованием внутренней нави- гационной системы сайта (меню, карты сайта, ссылки, баннеры и т. д.).

Для определения уровня поисковой доступности $k$-го информационного объекта, размещенного на официальном сайте $i$-й организации культуры, по $s$-му показателю, характеризующему общие критерии качества оказания услуг, применяется следующая схема (табл. 2).

Информация, размещенная на официальном сайте организации культуры, анализируется с помощью информационных объектов (см. табл. 3).

Интегральное значение показателей $i$-й организации культуры, определяемое путем анализа данных, полученных при изучении мнений получателей услуг $\left(N_{i}^{\text {удвв }}\right)$, рассчитывается по формуле:

$$
N_{i}^{\text {удовл }}=\sum_{j} \frac{1}{p_{i j}} \sum_{p} m_{i j p},
$$

где $m_{i j p}$ - значение показателя, сформированное $p$-м получателем услуг $i$-й организацией культуры по $j$-му показателю; $p_{i j}$ - количество получателей услуг, оценивших качество оказания услуг $i$-й организацией культуры по $j$-му показателю [3].

Значения по показателям, формируемые на основе изучения мнений получателей услуг, представлены в результирующей таблице 4.

Суммирующий показатель по данному конкретному учреждению выглядит следующим образом: $N_{i}=15+113=128$.

Результаты проведения независимой оценки качества оказания услуг организациями культуры Курской области обсуждаются на заседании Общественного совета, где формируются предложения по улучшению качества деятельности организаций культуры. Они представляются соответственно в органы местного самоуправления, органы государственной власти субъектов Российской Федерации, Министерство культуры Российской Федерации, которые рассматривают полученную информацию и учитывают ее при выработке мер по совершенствованию деятельности организаций культуры.

Схема определения уровня поисковой доступности

\begin{tabular}{|c|c|c|c|}
\hline № & $\begin{array}{c}\text { Поиск информационного } \\
\text { объекта }\end{array}$ & $\begin{array}{c}\text { Уровень поисковой } \\
\text { доступности }\left(Z_{i k s}\right) \text { в баллах }\end{array}$ & $\begin{array}{c}\text { Открытость и доступность } \\
\text { для пользователя }\end{array}$ \\
\hline 1 & $\begin{array}{l}\text { Информационный объект най- } \\
\text { ден на официальном сайте }\end{array}$ & 1 & $\begin{array}{l}\text { Открыт и доступен для поль- } \\
\text { зователя }\end{array}$ \\
\hline 2 & $\begin{array}{l}\text { Информационный объект не } \\
\text { найден на официальном сайте }\end{array}$ & 0 & Недоступен для пользователя \\
\hline
\end{tabular}

Таблица 2 


\section{Перечень информационных объектов \\ (Областное бюджетное учреждение культуры «Курчатовский государственный краеведческий музей»)}

Наименование показателя, характеризующего общие критерии качества оказания услуг организациями культуры в соответствии с приказом № $2542(s)$

1.1 Наличие общей информа-

$\left(s_{1}\right)$ ции об организации культуры на официальном сайте организации культуры в сети «Интернет» (приказ Минкультуры России от 20.02.2015 № 277)

\begin{tabular}{|c|c|c|}
\hline & Наименование информационного объекта $(k)$ & $\begin{array}{c}\text { Уровень } \\
\text { поисковой } \\
\text { доступности } \\
\left(\boldsymbol{Z}_{\text {iks }}\right) \text { в баллах }\end{array}$ \\
\hline 1 & Полное наименование организации культуры & 1 \\
\hline 2 & Сокращенное наименование организации культуры & 1 \\
\hline 3 & Почтовый адрес организации культуры & 1 \\
\hline 4 & $\begin{array}{l}\text { Схема размещения организации культуры, схема } \\
\text { проезда }\end{array}$ & 1 \\
\hline 5 & $\begin{array}{l}\text { Дата создания организации культуры, сведения об уч- } \\
\text { редит еле (учредителях) }\end{array}$ & 1 \\
\hline 6 & $\begin{array}{l}\text { Учредительные документы (копия устава, свидетель- } \\
\text { ство о государственной регистрации, решение учреди- } \\
\text { теля о создании и назначении руководителя организа- } \\
\text { ции культуры, положения о филиалах и представи- } \\
\text { тельствах) }\end{array}$ & 1 \\
\hline 7 & Режим, график работы организации культуры & 1 \\
\hline 8 & Контактные телефоны & 1 \\
\hline 9 & Адрес электронной почты & 1 \\
\hline 10 & $\begin{array}{l}\text { Фамилии, имена, отчества, должности руководящего } \\
\text { состава организации культуры, ее структурных подраз- } \\
\text { делений и филиалов (при их наличии). }\end{array}$ & 1 \\
\hline 1 & Сведения о видах предоставляемых услуг & 0 \\
\hline 2 & $\begin{array}{l}\text { Копии нормативных правовых актов, устанавливаю- } \\
\text { щих цены (тарифы) на услуги либо порядок их уста- } \\
\text { новления }\end{array}$ & 0 \\
\hline 3 & $\begin{array}{l}\text { Перечень оказываемых платных услуг, цены (тарифы) } \\
\text { на услуги }\end{array}$ & 1 \\
\hline 4 & $\begin{array}{l}\text { Копия плана финансово-хозяйственной деятельности } \\
\text { организации культуры, утвержденного в установлен- } \\
\text { ном законодательством Российской Федерации поряд- } \\
\text { ке, или бюджетной сметы (информация об объеме пре- } \\
\text { доставляемых услуг) }\end{array}$ & 1 \\
\hline 5 & $\begin{array}{l}\text { Информация о материально-техническом обеспечении } \\
\text { предоставления услуг организацией культуры }\end{array}$ & 0 \\
\hline 6 & $\begin{array}{l}\text { Копии лицензий на осуществление деятельности, под- } \\
\text { лежащей лицензированию в соответствии с законода- } \\
\text { тельством Российской Федерации }\end{array}$ & 0 \\
\hline 7 & Информация о планируемых мер оприятиях & 1 \\
\hline 8 & $\begin{array}{l}\text { Информация о выполнении государственного (муни- } \\
\text { ципального) задания, отчет о результатах деятельности } \\
\text { учреждения }\end{array}$ & 1 \\
\hline 9 & $\begin{array}{l}\text { Результаты независимой оценки качества оказания ус- } \\
\text { луг организациями культуры, а также предложения об } \\
\text { улучшении качества их деятельности }\end{array}$ & 1 \\
\hline 10 & План по улучшению качества работы организации & 0 \\
\hline & Итого & 15 \\
\hline
\end{tabular}




\section{Значения по показателям, формируемые на основе изучения мнений получателей услуг Областного бюджетного учреждения культуры «Курчатовский государственный краеведческий музей»}

\begin{tabular}{|c|c|c|c|c|c|c|c|c|}
\hline № & Показатель & $\begin{array}{c}\text { Варианты ответов на вопросы } \\
\text { при изучении мнений получателей услуг }\end{array}$ & $\begin{array}{r}\text { Вари } \\
\text { ты зн } \\
\text { чени } \\
\text { в балј } \\
\end{array}$ & & $\begin{array}{l}\text { Частота } \\
\text { распре- } \\
\text { делений }\end{array}$ & $\begin{array}{c}\text { Сумма } \\
\text { баллов по } \\
\text { каждому } \\
\text { вопросу } \\
\end{array}$ & $\begin{array}{c}\text { Кол-во } \\
\text { ответив- } \\
\text { ших на } \\
\text { вопрос } \\
\end{array}$ & $\begin{array}{c}\text { Средняя } \\
\text { оценка } \\
\text { по во- } \\
\text { просу } \\
\end{array}$ \\
\hline 1 & 2 & 3 & 4 & & 5 & 6 & 7 & 8 \\
\hline$j 1$ & \multirow{5}{*}{\begin{tabular}{|l|} 
Доступность и акту- \\
альность информации \\
о деятельности орга- \\
низации культуры, \\
размещенной на тер- \\
ритории организации
\end{tabular}} & Отлично, все устраивает & 10 & & 54 & 540 & \multirow{5}{*}{200} & \multirow{5}{*}{8,088} \\
\hline & & В целом хорошо & 7,5 & & 139 & 1042,5 & & \\
\hline & & $\begin{array}{l}\text { Удовлетворительно, незначительные } \\
\text { недостатки }\end{array}$ & 5 & & 7 & 35 & & \\
\hline & & Плохо, много недостатков & 2,5 & & 0 & 0 & & \\
\hline & & $\begin{array}{l}\text { Неудовлетворительно, совершенно } \\
\text { не устраивает }\end{array}$ & 0 & & 0 & 0 & & \\
\hline \multirow[t]{2}{*}{$j^{2}$} & \multirow{5}{*}{$\begin{array}{l}\text { Комфортность усло- } \\
\text { вий пребывания в ор- } \\
\text { ганизации культуры }\end{array}$} & Отлично, все устраивает & 10 & & 49 & 490 & \multirow{5}{*}{199} & \multirow{5}{*}{7,726} \\
\hline & & В целом хорошо & 7,5 & & 130 & 975 & & \\
\hline & & $\begin{array}{l}\text { Удовлетворительно, незначительные } \\
\text { недостатки }\end{array}$ & 5 & & 9 & 45 & & \\
\hline & & Плохо, много недостатков & 2,5 & & 11 & 27,5 & & \\
\hline & & $\begin{array}{l}\text { Неудовлетворительно, совершенно } \\
\text { не устраивает }\end{array}$ & 0 & & 0 & 0 & & \\
\hline \multirow[t]{5}{*}{$\overline{j 3}$} & \multirow{5}{*}{$\begin{array}{l}\text { Дополнительные ус- } \\
\text { луги и доступность их } \\
\text { получения }\end{array}$} & Отлично, все устраивает & 10 & & 31 & 310 & \multirow{5}{*}{199} & \multirow{5}{*}{7,651} \\
\hline & & В целом хорошо & 7,5 & & 151 & 1132,5 & & \\
\hline & & $\begin{array}{l}\text { Удовлетворительно, незначительные } \\
\text { недостатки }\end{array}$ & 5 & & 15 & 75 & & \\
\hline & & Плохо, много недостатков & 2,5 & & 2 & 5 & & \\
\hline & & $\begin{array}{l}\text { Неудовлетворительно, совершенно } \\
\text { не устраивает }\end{array}$ & 0 & & 0 & 0 & & \\
\hline \multirow[t]{5}{*}{ j4 } & \multirow{5}{*}{$\begin{array}{l}\text { Удобство пользования } \\
\text { электронными серви- } \\
\text { сами, предоставляе- } \\
\text { мыми организацией } \\
\text { культуры (в том числе } \\
\text { с помощью мобиль- } \\
\text { ных устройств) }\end{array}$} & Отлично, все устраивает & 10 & & 7 & 70 & \multirow{5}{*}{199} & \multirow{5}{*}{6,809} \\
\hline & & В целом хорошо & 7,5 & & 141 & 1057,5 & & \\
\hline & & $\begin{array}{l}\text { Удовлетворительно, незначительные } \\
\text { недостатки }\end{array}$ & 5 & & 40 & 200 & & \\
\hline & & Плохо, много недостатков & 2,5 & & 11 & 27,5 & & \\
\hline & & $\begin{array}{l}\text { Неудовлетворительно, совершенно } \\
\text { не устраивает }\end{array}$ & 0 & & 0 & 0 & & \\
\hline \multirow[t]{5}{*}{$j 5$} & \multirow{5}{*}{$\begin{array}{l}\text { Удобство графика ра- } \\
\text { боты организации } \\
\text { культуры }\end{array}$} & Отлично, очень удобно & 10 & & 98 & 980 & \multirow{5}{*}{199} & \multirow{5}{*}{8,508} \\
\hline & & В целом хорошо & 7,5 & & 86 & 645 & & \\
\hline & & $\begin{array}{l}\text { Удовлетворительно, незначительные } \\
\text { недостатки }\end{array}$ & 5 & & 12 & 60 & & \\
\hline & & Плохо, много недостатков & 2,5 & & 3 & 7,5 & & \\
\hline & & Совершенно не удобно & 0 & & 0 & 0 & & \\
\hline \multirow[t]{8}{*}{ j6 } & \multirow[t]{8}{*}{$\begin{array}{l}\text { Доступность услуг для } \\
\text { инвалидов }\end{array}$} & \multirow{2}{*}{$\begin{array}{l}\text { Обеспечение возможности для инва- } \\
\text { лидов посадки в транспортное сред- } \\
\text { ство и высадки из него перед входом } \\
\text { в организацию культуры, в том чис- } \\
\text { ле с использованием кресла-коляски } \\
\end{array}$} & да & 2 & 156 & 312 & \multirow[b]{2}{*}{200} & \multirow[b]{2}{*}{1,560} \\
\hline & & & нет & 0 & 44 & 0 & & \\
\hline & & \multirow{2}{*}{$\begin{array}{l}\text { Оснащение организации специальны- } \\
\text { ми устройствами для доступа инвали- } \\
\text { дов (оборудование входных зон, раз- } \\
\text { движные двери, приспособленные пе- } \\
\text { рила, доступные санитарно-гигиени- } \\
\text { ческие помещения, звуковые устрой- } \\
\text { ства для инвалидов по зрению и т. п.) } \\
\end{array}$} & да & 2 & 35 & 70 & \multirow{2}{*}{200} & 0,350 \\
\hline & & & нет & 0 & 165 & 0 & & \\
\hline & & $\begin{array}{l}\text { Наличие сопровождающего персона- } \\
\text { ла и возможности самостоятельного }\end{array}$ & да & 2 & 155 & 310 & 199 & 1558 \\
\hline & & $\begin{array}{l}\text { передвижения по территории орга- } \\
\text { низации }\end{array}$ & нет & 0 & 44 & 0 & & \\
\hline & & Компетентность работы персонала с & да & 2 & 186 & 372 & 10 & 9 \\
\hline & & посетителями-инвалидами & нет & 0 & 13 & 0 & נוצו & 1,003 \\
\hline
\end{tabular}


Продолжение таблищы 4

\begin{tabular}{|c|c|c|c|c|c|c|c|}
\hline № & Показатель & $\begin{array}{c}\text { Варианты ответов на вопросы } \\
\text { при изучении мнений получателей услуг }\end{array}$ & \begin{tabular}{|c} 
Вариан- \\
ты зна- \\
чений \\
в баллах \\
\end{tabular} & $\begin{array}{l}\text { Частота } \\
\text { распре- } \\
\text { делений }\end{array}$ & $\begin{array}{c}\text { Сумма } \\
\text { баллов по } \\
\text { каждому } \\
\text { вопросу } \\
\end{array}$ & $\begin{array}{c}\text { Кол-во } \\
\text { ответив- } \\
\text { ших на } \\
\text { вопрос }\end{array}$ & $\begin{array}{c}\text { Средняя } \\
\text { оценка } \\
\text { по во- } \\
\text { просу }\end{array}$ \\
\hline \multirow[t]{4}{*}{1} & 2 & 3 & 4 & 5 & 6 & 7 & 8 \\
\hline & & \multirow{2}{*}{\begin{tabular}{|l|} 
Размещение информации, необходи- \\
мой для обеспечения беспрепятствен- \\
ного доступа инвалидов к учреждению \\
и услугам (дублирование необходимой \\
для получения услуги звуковой и зри- \\
тельной информации, а также надпи- \\
сей, знаков и иной текстовой и графи- \\
ческой информации знаками, выпол- \\
ненными рельефно-точечным шриф- \\
том Брайля и на контрастном фоне) \\
\end{tabular}} & да & 13 & 26 & \multirow[b]{2}{*}{199} & \multirow[b]{2}{*}{0,131} \\
\hline & & & \begin{tabular}{|l|l|} 
нет & 0 \\
\end{tabular} & 186 & 0 & & \\
\hline & & & & & & & 5,468 \\
\hline$j 7$ & \multirow{5}{*}{$\begin{array}{l}\text { Соблюдение режима } \\
\text { работы организацией } \\
\text { культуры }\end{array}$} & Отлично, все устраивает & 10 & 150 & 1500 & \multirow{5}{*}{199} & \multirow{5}{*}{9,259} \\
\hline & & В целом хорошо & 7,5 & 39 & 292,5 & & \\
\hline & & $\begin{array}{l}\text { Удовлетворительно, незначительные } \\
\text { нарушения }\end{array}$ & 5 & 10 & 50 & & \\
\hline & & Плохо, много нарушений & 2,5 & 0 & 0 & & \\
\hline & & $\begin{array}{l}\text { Неудовлетворительно, совершенно } \\
\text { не соблюдается }\end{array}$ & 0 & 0 & 0 & & \\
\hline \multirow[t]{5}{*}{ j8 } & \multirow{5}{*}{$\begin{array}{l}\text { Соблюдение установ- } \\
\text { ленных (заявленных) } \\
\text { сроков предоставле- } \\
\text { ния услуг организаци- } \\
\text { ей культуры }\end{array}$} & Отлично, все устраивает & 10 & 136 & 1360 & \multirow{5}{*}{199} & \multirow{5}{*}{9,070} \\
\hline & & В целом хорошо & 7,5 & 53 & 397,5 & & \\
\hline & & $\begin{array}{l}\text { Удовлетворительно, незначительные } \\
\text { нарушения }\end{array}$ & 5 & 9 & 45 & & \\
\hline & & Плохо, много нарушений & 2,5 & 1 & 2,5 & & \\
\hline & & $\begin{array}{l}\text { Неудовлетворительно, совершенно } \\
\text { не соблюдаются }\end{array}$ & 0 & 0 & 0 & & \\
\hline \multirow[t]{5}{*}{ j9 } & \multirow{5}{*}{$\begin{array}{l}\text { Доброжелательность и } \\
\text { вежливость персонала } \\
\text { организации культуры }\end{array}$} & Отлично, все устраивает & 10 & 169 & 1690 & \multirow{5}{*}{199} & \multirow{5}{*}{9,523} \\
\hline & & В целом хорошо & 7,5 & 22 & 165 & & \\
\hline & & Удовлетворительно & 5 & 8 & 40 & & \\
\hline & & Плохо & 2,5 & 0 & 0 & & \\
\hline & & Неудовлетворительно & 0 & 0 & 0 & & \\
\hline \multirow[t]{5}{*}{ j10 } & \multirow{5}{*}{$\begin{array}{l}\text { Компетентность пер- } \\
\text { сонала организации } \\
\text { культуры }\end{array}$} & Отлично, все устраивает & 10 & 159 & 1590 & \multirow{5}{*}{199} & \multirow{5}{*}{9,410} \\
\hline & & В целом хорошо & 7,5 & 33 & 247,5 & & \\
\hline & & Удовлетворительно & 5 & 7 & 35 & & \\
\hline & & Плохо & 2,5 & 0 & 0 & & \\
\hline & & Неудовлетворительно & 0 & 0 & 0 & & \\
\hline \multirow[t]{5}{*}{ j11 } & \multirow{5}{*}{$\begin{array}{l}\text { Удовлетворенность } \\
\text { качеством оказания } \\
\text { услуг организацией } \\
\text { культуры в целом }\end{array}$} & Отлично, все устраивает & 10 & 133 & 1330 & \multirow{5}{*}{198} & \multirow{5}{*}{9,104} \\
\hline & & В целом хорошо & 7,5 & 59 & 442,5 & & \\
\hline & & $\begin{array}{l}\text { Удовлетворительно, незначительные } \\
\text { недостатки }\end{array}$ & 5 & 6 & 15 & & \\
\hline & & Плохо, много недостатков & 2,5 & 0 & 0 & & \\
\hline & & $\begin{array}{l}\text { Неудовлетворительно, совершенно } \\
\text { не устраивает }\end{array}$ & 0 & 0 & 0 & & \\
\hline$j 12$ & Удовлетворенность & Отлично, все устраивает & 10 & 16 & 160 & & \\
\hline & материально-техни- & В целом хорошо & 7,5 & 86 & 645 & & \\
\hline & $\begin{array}{l}\text { ческим обеспечением } \\
\text { организации культуры }\end{array}$ & $\begin{array}{l}\text { Удовлетворительно, незначительные } \\
\text { недостатки }\end{array}$ & 5 & 78 & 390 & 198 & 6,225 \\
\hline & & Плохо, много недостатков & 2,5 & 15 & 37,5 & & \\
\hline & & $\begin{array}{l}\text { Неудовлетворительно, совершенно } \\
\text { не устраивает }\end{array}$ & 0 & 3 & 0 & & \\
\hline$j 13$ & Удовлетворенность ка- & Отлично, все устраивает & 10 & 78 & 780 & & \\
\hline & чеством и полнотой & В целом хорошо & 7,5 & 88 & 660 & & \\
\hline & $\begin{array}{l}\text { информации о деятель- } \\
\text { ности организации }\end{array}$ & $\begin{array}{l}\text { Удовлетворительно, незначительные } \\
\text { недостатки }\end{array}$ & 5 & 27 & 135 & & \\
\hline & культуры, размещенной & Плохо, много недостатков & 2,5 & 2 & 5 & 198 & 7,980 \\
\hline & $\begin{array}{l}\text { на официальном сайте } \\
\text { организации культуры } \\
\text { в сети «Интернет» }\end{array}$ & $\begin{array}{l}\text { Неудовлетворительно, совершенно } \\
\text { не устраивает }\end{array}$ & 0 & 3 & 0 & & \\
\hline
\end{tabular}


Окончание таблиџьы 4

\begin{tabular}{|c|c|c|c|c|c|c|c|}
\hline № & Показатель & $\begin{array}{c}\text { Варианты ответов на вопросы } \\
\text { при изучении мнений получателей услуг }\end{array}$ & $\begin{array}{c}\text { Вариан- } \\
\text { ты зна- } \\
\text { чений } \\
\text { в баллах } \\
\end{array}$ & $\begin{array}{l}\text { Частота } \\
\text { распре- } \\
\text { делений }\end{array}$ & $\begin{array}{c}\text { Сумма } \\
\text { баллов по } \\
\text { каждому } \\
\text { вопросу } \\
\end{array}$ & $\begin{array}{c}\text { Кол-во } \\
\text { ответив- } \\
\text { ших на } \\
\text { вопрос } \\
\end{array}$ & $\begin{array}{c}\text { Средняя } \\
\text { оценка } \\
\text { по во- } \\
\text { просу } \\
\end{array}$ \\
\hline 1 & 2 & 3 & 4 & 5 & 6 & 7 & 8 \\
\hline \multirow[t]{5}{*}{$j 14$} & \multirow{5}{*}{$\begin{array}{l}\text { Удовлетворенность } \\
\text { качеством и содержа- } \\
\text { нием полиграфиче- } \\
\text { ских материалов орга- } \\
\text { низации культуры }\end{array}$} & Отлично, все устраивает & 10 & 85 & 850 & \multirow{5}{*}{198} & \multirow{5}{*}{8,182} \\
\hline & & В целом хорошо & 7,5 & 84 & 630 & & \\
\hline & & $\begin{array}{l}\text { Удовлетворительно, незначительные } \\
\text { недостатки }\end{array}$ & 5 & 27 & 135 & & \\
\hline & & Плохо, много недостатков & 2,5 & 2 & 5 & & \\
\hline & & $\begin{array}{l}\text { Неудовлетворительно, совершенно } \\
\text { не устраивает }\end{array}$ & 0 & 0 & 0 & & \\
\hline & & & & & Итого: & \multicolumn{2}{|l|}{113,003} \\
\hline
\end{tabular}

В соответствии с приказом Минфина России № 116н от 22 июля 2015 г. результаты проведения независимой оценки качества оказания услуг организациями культуры размещаются на официальных сайтах Министерства культуры Российской Федерации, органов исполнительной власти субъектов Российской Федерации и органов местного самоуправления, на официальном сайте для размещения информации о государственных и муниципальных учреждениях в сети «Интернет» [8].

Выводы, которые следуют из вышеизложенного, касаются раскрытия латентных возможностей учреждений культуры Курской области, выявленных в процессе проведения независимой оценки качества. Прежде всего это работа с людьми с ограниченными возможностями здоровья, которые должны иметь равный доступ к услугам культурно-досуговых организаций. Сюда относится не только обеспечение их мобильности, но и дополнительное техническое сопровождение в самой организации. Не все сайты снабжены версиями для слабовидящих людей, что также должно являться приоритетом в работе организации. Исследование качества оказания услуг 2017 г. в Курской области находится в процессе отработки основных позиций для определения стратегических направлений развития сферы культуры региона.

\section{СПИСОК ЛИТЕРАТУРЫ}

1. Основы законодательства Российской Федерации о культуре : (утв. ВС РФ 09.10.1992 № 3612-1) : (ред. от 28.11.2015) : (с изм. и доп., вступ. в силу с 01.01.2016). - Электрон. текстовые дан. - Режим доступа: http://www.consultant.ru/document/cons doc_LAW_1870/(дата обращения: 01.06.2017). - Загл. с экрана.
2. Приказ комитета по культуре Курской области № 01-03/56 от 18 апреля 2016 г. «Об утверждении плана мероприятий по проведению независимой оценки качества работы организаций, оказывающих услуги в сфере культуры на 20162017 годы». - Электрон. текстовые дан. - Режим доступа: http://культура46.pф/2-uncategorised/73nezavisimaya-otsenka-kachestva-v-2016-2018-gg/ (дата обращения: 01.06.2017). - Загл. с экрана.

3. Приказ Министерства культуры Российской Федерации от 20.02.2015 № 277 «Об утверждении требований к содержанию и форме предоставления информации о деятельности организаций культуры, размещаемой на официальных сайтах уполномоченного федерального органа исполнительной власти, органов государственной власти субъектов Российской Федерации, органов местного самоуправления и организаций культуры в сети “Интернет”». - Электрон. текстовые дан. - Режим доступа: http://mkrf.ru/open-ministry/quality/ detail.php?ID=653325 (дата обращения: 01.06.2017). Загл. с экрана.

4. Приказ Министерства культуры Российской Федерации от 25.02.2015 № 288 «Об утверждении показателей, характеризующих общие критерии оценки качества оказания услуг организациями культуры» : (с изм. от 07.08.2015 № 2168). - Электрон. текстовые дан. - Режим доступа: http:// www.rosmintrud.ru/docs/mintrud/analytics/66 (дата обращения: 01.06.2017). - Загл. с экрана.

5. Приказ Министерства культуры Российской Федерации от 07.08.2015 № 2169 «Об угверждении перечня организаций культуры, в отношении которых не проводится независимая оценка качества оказания услуг в сфере культуры». - Электрон. текстовые дан. - Режим доступа: http://mkrf.ru/ open-ministry/quality/detail.php?ID=705454\&t=main (дата обращения: 01.06.2017). - Загл. с экрана.

6. Приказ Министерства культуры Российской Федерации от 22 ноября 2016 г. № 2542 «Об угверждении показателей, характеризующих общие критерии оценки качества оказания услуг организациями куль- 
туры». - Электрон. текстовые дан. - Режим доступа: http://mkrf.ru/documents/orders/detail.php?ID=1269194 (дата обращения: 01.06.2017). - Загл. с экрана.

7. Приказ Министерства культуры Российской Федерации от 07 марта 2017 г. № 261 «Об утверждении Методических рекомендаций по проведению независимой оценки качества оказания услуг организациями культуры». - Электрон. текстовые дан. - Режим доступа: http://www.garant.ru/products/ ipo/prime/doc/71540064/. - Загл. с экрана.

8. Приказ Министерства финансов России от 22.07.2015 № 116н «О составе информации о результатах независимой оценки качества образовательной деятельности организаций, осуществляющих образовательную деятельность, оказания услуг организациями культуры, социального обслуживания, медицинскими организациями, размещаемой на официальном сайте для размещения информации о государственных и муниципальных учреждениях в информационно-телекоммуникационной сети "Интернет” и порядке ее размещения». Электрон. текстовые дан. - Режим доступа: http:// minfin.ru/ru/document/?id_4=69408/ (дата обращения: 01.06.2017). - Загл. с экрана.

9. Пример расчета значений показателей, характеризующих общие критерии оценки качества оказания услуг организациями культуры. - Электрон. текстовые дан. - Режим доступа: https://www. mkrf.ru/ documents/primer-rascheta-znacheniy-pokazateleykharakterizuyushchikh-obshchie-kriterii-otsenkikachestva-okaz/ (дата обращения: 01.06.2017). - Загл. с экрана.

10. Рейтинг муниципальных районов и городских округов в сфере культуры по итогам 2016 года. Электрон. текстовые дан. - Режим доступа: http://культура46.pф/2-uncategorised/149-rejting-munitsipalnykhrajonov-i-gorodskikh-okrugov-v-sfere-kultury-poitogam-2016-goda/ (дата обращения: 01.06.2017). - Загл. с экрана.

11. Указ Президента Российской Федерации от 07.05.2012 № 597 «О мероприятиях по реализации государственной социальной политики». - Электpoн. текстовые дан. - Режим доступа: https://rg.ru/ 2012/05/09/soc-polit-dok.html/э (дата обращения: 01.06.2017). - Загл. с экрана.

12. Andriyanova, T. V. Organizations of culture in Kursk region: modern trends of development /T. V. Andriyanova // Modern problems of fundamental and applied sciences : Proceedings of the Conference. Praha : Printing house, 2016. - P. 90-94.

\section{REFERENCES}

1. Osnovyzakonodatelstva Rossiyskoy Federatsii o kulture: (utv. VS RF 09.10.1992 N 3612-1): (red. ot
28.11.2015): (s izm. i dop., vstup. v silu s 01.01.2016) [Fundamentals of the Legislation of the Russian Federation about Culture (Approved by the Supreme Court of Russia on October 9, 1992 no. 3612-1: (amend. of November 28, 2015): (with amend. and add. come in force from January 1, 2016)]. URL: http:/www. consultant.ru/document/cons_doc_LAW_1870/ (accessed June 1, 2017).

2. Prikaz komiteta po kulture Kurskoy oblasti № 01-03/56 ot 18 aprelya $2016 \mathrm{~g}$. «Ob utverzhdenii plana meropriyatiy po provedeniyu nezavisimoy otsenki kachestva raboty organizatsiy, okazyvayushchikh uslugi v sfere kultury na 20162017 gody» [Order of Committee on Culture of the Kursk Region no. 01-03/56 of April 18, 2016 “On Approval of Action Plan on Independent Evaluation of the Work of Organizations Providing Services in the Sphere of Culture for 2016-2017']. URL: http://культура46.pф/2-uncategorised/73-nezavisimaya-otsenkakachestva-v-2016-2018-gg/ (accessed June 1, 2017).

3. Prikaz Ministerstva kultury Rossiyskoy Federatsii ot 20.02.2015 № 277 «Ob utverzhdenii trebovaniy $k$ soderzhaniyu $i$ forme predostavleniya informatsii o deyatelnosti organizatsiy kultury, razmeshchaemoy na ofitsialnykh saytakh upolnomochennogo federalnogo organa ispolnitelnoy vlasti, organov gosudarstvennoy vlasti subyektov Rossiyskoy Federatsii, organov mestnogo samoupravleniya $i$ organizatsiy kultury $v$ set $i$ "Internet"” [Order of the Ministry of Culture of the Russian Federation of February 20, 2015 no. 277 “On Approval of Requirements to Content and Form of Providing Information on the Activities of Cultural Organizations Published on the Official Websites of the Authorized Federal Body of Executive Power, Bodies of State Power of Subjects of the Russian Federation, Bodies of Local Self-Government and Culture Organizations on Internet"]. URL: http://mkrf. ru>open-ministry/quality/detail.php? ID $=653325$ / (accessed June 1, 2017).

4. Prikaz Ministerstva kultury Rossiyskoy Federatsii ot 25.02.2015 № 288 «Ob utverzhdenii pokazateley, kharakterizuyushchikh obshchie kriterii otsenki kachestva okazaniya uslug organizatsiyami kultury» (s izm. ot 07.08.2015 № 2168) [Order of the Ministry of Culture of the Russian Federation of February 25, 2015 no. 288 “On Approval of Indicators of the General Criteria for Evaluating the Quality of Services Provided by Culture Organizations" (with amendments of August 7, 2015 no. 2168)]. URL: http://www.rosmintrud.ru/docs/ mintrud/analytics/66 (accessed June 1, 2017).

5. Prikaz Ministerstva kultury Rossiyskoy Federatsii ot 07.08.2015 № 2169 «Ob utverzhdenii perechnya organizatsiy kultury, $v$ otnoshenii kotorykh ne provoditsya nezavisimaya otsenka 
kachestva okazaniya uslug v sfere kultury» [Order of the Ministry of Culture of the Russian Federation of August 7, 2015 no. 2169 "On Approval of the List of Culture Organizations, Which Are Not Evaluated Independently on the Subject of Services Quality in the Sphere of Culture"]. URL: http://mkrf.ru/openministry/quality/detail.php? ID=705454\&t=main (accessed June 1, 2017).

6. Prikaz Ministerstva kultury Rossiyskoy Federatsii ot 22 noyabrya 2016 g. N $2542 « O b$ utverzhdenii pokazateley, kharakterizuyushchikh obshchie kriterii otsenki kachestva okazaniya uslug organizatsiyami kultury" [Order of the Ministry of Culture of the Russian Federation of November 22, 2016 no. 2542 “On Approval of Indicators of General Criteria for Assessing the Quality of Services Provided by Culture Organizations"]. URL: http://http://mkrf.ru/ documents/orders/detail.php?ID=1269194 (accessed June 1, 2017).

7. Prikaz Ministerstva kultury Rossiyskoy Federatsii ot 07 marta 2017 g. № 261 «Ob utverzhdenii Metodicheskikh rekomendatsiy po provedeniyu nezavisimoy otsenki kachestva okazaniya uslug organizatsiyami kultury» [Order of the Ministry of Culture of the Russian Federation of March 7, 2017 no. 261 "On Approval of Methodical Recommendations for Independent Assessment of Quality of Services Provided by Culture Organizations"]. URL: http://www.garant.ru/products/ ipo/prime/doc/71540064/ (accessed June 1, 2017).

8. Prikaz Ministerstva finansov Rossii ot 22.07.2015 № 116n «O sostave informatsii o rezultatakh nezavisimoy otsenki kachestva obrazovatelnoy deyatelnosti organizatsiy, osushchestvlyayushchikh obrazovatelnuyu deyatelnost, okazaniya uslug organizatsiyami kultury, sotsialnogo obsluzhivaniya, meditsinskimi organizatsiyami, razmeshchaemoy na ofitsialnom sayte dlya razmeshcheniya informatsii o gosudarstvennykh i munitsipalnykh uchrezhdeniyakh $v$ informatsionno-telekommunikatsionnoy seti
«Internet» i poryadke ee razmeshcheniya» [Order of the Ministry of Finance of Russia of July 22, 2015 no. $116 n$ "On the Information about the Results of the Independent Evaluation of Quality of Educational Activities of the Organizations Performing Educational Activities, Services, Organizations, Culture, Social Services, Medical Organizations Published on the Official Website for Providing Information about State and Municipal Institutions in the InformationTelecommunication Network "Internet" and about the Practice of Its Publication"]. URL: http://minfin.ru/ru/ document/?id_4=69408/(accessed June 1, 2017).

9. Primer rascheta znacheniy pokazateley, kharakterizuyushchikh obshchie kriterii otsenki kachestva okazaniya uslug organizatsiyami kultury [Example of Calculating the Values of Indicators of General Criteria for Assessing the Quality of Services Provided by Culture Organizations]. URL: https:// www.mkrf.ru/documents/primer-rascheta-znacheniypokazateley-kharakterizuyushchikh-obshchie-kriteriiotsenki-kachestva-okaz/ (accessed June 1, 2017).

10. Reyting munitsipalnykh rayonov $i$ gorodskikh okrugov v sfere kultury po itogam 2016 goda [The Rating of Municipal Districts and City Districts in the Sphere of Culture at the End of 2016]. URL: http:// культура46.pф/2-uncategorised/149-rejtingmunitsipalnykh-rajonov-i-gorodskikh-okrugov-vsfere-kultury-po-itogam-2016-goda/ (accessed June 1, 2017).

11. Ukaz Prezidenta Rossiyskoy Federatsii ot 07.05.2012 № 597 «O meropriyatiyakh po realizatsii gosudarstvennoy sotsialnoy politiki» [Decree of the President of the Russian Federation of May 7, 2012 no. 597 “On Measures for Implementing State Social Policy”]. URL: https://rg.ru/2012/05/09/soc-politdok.html/ (accessed June 1, 2017).

12. Andriyanova T.V. Organizations of culture in Kursk region: modern trends of development. Modern problems of fundamental and applied sciences: Proceedings of the Conference. Praha, Printing house, 2016, pp. 90-94.

\section{Information about the Author}

Tatyana V. Andriyanova, Candidate of Sociological Sciences, Associate Professor, Department of Sociology and Political Science, Kursk State University, Radishcheva St., 29, 305004 Kursk, Russian Federation, andriyanova.tv@gmail.com.

\section{Информация об авторе}

Татьяна Владимировна Андриянова, кандидат социологических наук, доцент кафедры социологии и политологии, Курский государственный университет, ул. Радищева, 29, 305004 г. Курск, Российская Федерация, andriyanova.tv@gmail.com. 